Canadian

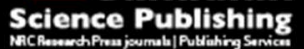

Canadian Journal of Civil Engineering Revue canadienne de génie civil

\title{
Parametric based study for design of liquid-filled elevated tanks
}

\begin{tabular}{|r|l|}
\hline Journal: & Canadian Journal of Civil Engineering \\
\hline Manuscript ID & cjce-2015-0218.R1 \\
\hline Danuscript Type: & Article \\
\hline Complete List of Authors: & $\begin{array}{l}\text { Moslemi, Mehdi; Ryerson University, Civil Engineering } \\
\text { Ghaemmaghami, Amirreza; Ryerson University } \\
\text { Kianoush, M. Reza; Ryerson University, Dept. of Civil Engineering }\end{array}$ \\
\hline Keyword: & $\begin{array}{l}\text { design < type of paper to review, response-earthquake load < Struct. Eng. } \\
\text { \& Constr.Mate, structures < Struct. Eng. \& Constr.Mate, structural } \\
\text { engineering < Computer Applications, english only < type of paper to } \\
\text { review }\end{array}$ \\
\hline
\end{tabular}

SCHOLARONE $^{\text {Ix }}$

Manuscripts 


\title{
Parametric based study for design of liquid-filled elevated tanks
}

\author{
Mehdi Moslemi, Amir Reza Ghaemmaghami, and M. Reza Kianoush
}

M. Moslemi. Department of Civil Engineering, Ryerson University, 350 Victoria Street, Toronto, Ontario, M5B 2K3, Canada.

A.R. Ghaemmaghami. Department of Civil Engineering, Ryerson University, 350 Victoria Street, Toronto, Ontario, M5B 2K3, Canada.

M.R. Kianoush. Department of Civil Engineering, Ryerson University, 350 Victoria Street, Toronto, Ontario, M5B 2K3, Canada.

Corresponding author: M. R. Kianoush (e-mail: kianoush@ryerson.ca; Tel.: +1 4169795000 x 6455; Fax: +1 416 979 5122). 


\begin{abstract}
In this study, the dynamic behavior of elevated water tanks is investigated by performing a comprehensive parametric study on conical elevated tanks using the finite element technique. Through this study, a wide range of tank parameters and geometries typically found in practice is considered. To perform this parametric study, a parametric model capable of building any finite element models of a three-dimensional conical elevated tank with varying parameters is developed. As a result of this parametric study, pressure distribution graphs corresponding to both impulsive and convective hydrodynamic pressures can be generated by carrying out spectral analysis. These pressure graphs can be utilized simply in design applications for liquid-filled conical elevated tanks. The accuracy of the proposed pressure graphs is verified by comparing these results with those calculated using the previously verified finite element time-history analysis and also the "current practice".
\end{abstract}

Key words: elevated tank, finite element method, dynamic analysis, liquid containing. 


\section{Introduction}

Liquid storage tanks are lifeline structures which has become widespread during the last decades.

Liquid tanks are exposed to a wide range of seismic hazards and interaction with other sectors of built environment. Heavy damages have been reported due to strong earthquakes such as Niigata in 1964, Alaska in 1964, Parkfield in 1966, Imperial County in 1979, Coalinga in 1983, Northridge in 1994 and Kocaeli in 1999 some of which are reported by Haroun and Ellaithy (1985); Rai (2002); Sezen and Whittaker (2006). These heavy damages revealed a complex behavior of liquid containing structures during seismic events.

Housner (1963) formulated an idealization, commonly applied in civil engineering practice, for estimating liquid response in seismically excited rigid, rectangular and cylindrical tanks. In this method, the hydrodynamic pressure induced by seismic excitations is separated into impulsive and convective components using lumped mass approximation. Many current standards and guides such as ACI 350.3 (2006) and ACI 371R (2008) have adapted Housner's method with some modifications which were the results of subsequent studies by other researchers for seismic design of liquid storage tanks.

Later, Veletsos (1974) showed that the flexibility of the tank shell could have a significant effect on dynamic forces induced by horizontal ground motion in liquid-filled cylindrical containers. Veletsos et al. (1992) presented a refined method for evaluating the impulsive and convective components of response of liquid-storage tanks. They found that the convective components of response are insensitive to the flexibilities of the tank wall and supporting soils, and may be computed considering both the tank and the supporting medium to be rigid. 
An equivalent mechanical model for evaluating the dynamic response of elevated water tanks was proposed by Haroun and Ellaithy (1985). Dieterman (1993) investigated the dynamic response of slender water towers incorporating liquid-structure-foundation interaction using a lumped model. Livaoglu and Dogangun (2006) studied the applicability of mechanical and finite-element modelling techniques to fluid-structure-soil interaction problem for elevated water tanks. Massless foundation and substructure strategies were employed to address the soilstructure interaction problems while added mass approach was used for the fluid-structure interaction problems. It was observed that single lumped-mass models underestimated the base shear and the overturning moment of the tower for both fixed-base and flexible soil conditions which could lead to an unsafe design of RC elevated tanks. Seismic behavior of elevated tanks incorporating the fluid-structure-soil interaction effect was well studied using the FE technique by Livaoglu and Dogangun (2005; 2007). It was found that the effect of embedment on the sloshing response was negligible and therefore could be ignored in analysis/design of the elevated tanks.

El Damatty et al. (2005) performed an experimental study on liquid-filled combined vessels to further investigate the dynamic characteristics of such containers. Combined vessels consist of a conical steel section with a superimposed top cylindrical shell. Dutta (1995) and Dutta et al. (1996; 2000a) investigated the torsional behavior of elevated tanks with RC frame-type staging under seismic loading and indicated that many elevated tanks of this type having designed based on current codes and standards are very vulnerable to torsional excitements caused by translational seismic motions. In a later study by Dutta et al. (2000b) alternate staging configurations with better torsional behavior were proposed and lateral and torsional stiffness of each configuration was calculated using approximate closed-form expressions. 
Moslemi et al. (2011) evaluated the performance of conical elevated tanks under seismic motions using the FE method. The effects of liquid sloshing and tank wall flexibility were considered in the proposed FEM. The accuracy of the method was verified by comparing the obtained results with experimental and numerical values available in the literature. In this study, the finite element method (FEM) is used to evaluate the performance of elevated tanks supported on concrete shaft. The accuracy of this method in analysis of fluid-structure systems was verified in previous studies by the authors (Moslemi et al. 2011; Moslemi and Kianoush 2012; Ghaemmaghami et al. 2010). As a result, the same technique is employed here for seismic analysis of elevated water tanks.

The primary objective of the current study is carrying out a comprehensive parametric study on liquid-filled conical elevated tanks using a detailed FE technique in a three-dimensional space. Based on the results of this study, the convective and impulsive pressure values can be separately determined along the height of the tank wall for typical elevated water tanks found in practice today. The study covers a wide range of tank dimensions and geometries commonly found in today's practice. Through this parametric study, the normalized pressure distribution graphs corresponding to the convective and impulsive components are obtained for a wide range of varying parameters by carrying out FE spectral analyses on a large number of conical elevated tanks.

The validity of the calculated pressure graphs is investigated by comparing the results with those calculated by the pre-verified FE time history method as the control method. Furthermore, the obtained results are also compared with those recommended by "current practice". Full details of the "current practice" method can be found in the previous work by the authors (Moslemi et al. 2011) and therefore no further explanation is provided here. Based on the results 
of this study, the proposed normalized pressure graphs could be utilized with high level of accuracy for seismic design of liquid-filled conical elevated tanks.

\section{Finite element method and research methodology}

The general purpose computer code ANSYS $®$ is used to implement FE analyses. Displacement-based (D-Fluid) elements are used to simulate the fluid domain. D-Fluid elements use displacements as the variables in the fluid domain. These elements are considered as an extension of structural solid elements in which the element shear modulus is set to zero and the fluid bulk modulus, $\mathrm{K}$ is used to establish the elastic stress-strain relations. D-Fluid elements are particularly useful in modeling fluids contained within vessels having no net flow rate and can be employed for transient as well as free vibration analyses. The stress-strain relationship of the element is established using the stiffness matrix as follows:

$$
\left\{\begin{array}{l}
\varepsilon_{b u l k} \\
\gamma_{x y} \\
\gamma_{y z} \\
\gamma_{x z} \\
R_{x} \\
R_{y} \\
R_{z}
\end{array}\right\}=\left[\begin{array}{ccccccc}
1 / K & 0 & 0 & 0 & 0 & 0 & 0 \\
0 & 1 / S & 0 & 0 & 0 & 0 & 0 \\
0 & 0 & 1 / S & 0 & 0 & 0 & 0 \\
0 & 0 & 0 & 1 / S & 0 & 0 & 0 \\
0 & 0 & 0 & 0 & 1 / B & 0 & 0 \\
0 & 0 & 0 & 0 & 0 & 1 / B & 0 \\
0 & 0 & 0 & 0 & 0 & 0 & 1 / B
\end{array}\right]\left\{\begin{array}{l}
P \\
\tau_{x y} \\
\tau_{y z} \\
\tau_{x z} \\
M_{x} \\
M_{y} \\
M_{z}
\end{array}\right\}
$$

where $\varepsilon_{b u l k}=\frac{\partial u}{\partial x}+\frac{\partial v}{\partial y}+\frac{\partial w}{\partial z}=$ bulk strain

$\mathrm{K}=$ fluid elastic (bulk) modulus

$\mathrm{P}=$ pressure

$\gamma=$ shear strain

$\mathrm{S}=\mathrm{K} \times 10^{-9}$ (arbitrarily small number to give element some shear stability) 
$\tau=$ shear stress

$\mathrm{R}_{\mathrm{i}}=$ rotation about axis $\mathrm{i}$

$\mathrm{B}=\mathrm{K} \times 10^{-9}$ (arbitrarily small number to give element some rotational stability)

$\mathrm{M}_{\mathrm{i}}=$ twisting force about axis $\mathrm{i}$

Damping matrix of the element that relates the strain rates (strain differentiation with respect to time) to the stresses can also be defined as:

$$
\left\{\begin{array}{l}
\dot{\varepsilon}_{b u l k} \\
\dot{\gamma}_{x y} \\
\dot{\gamma}_{y z} \\
\dot{\gamma}_{x z} \\
\dot{R}_{x} \\
\dot{R}_{y} \\
\dot{R}_{z}
\end{array}\right\}=\left[\begin{array}{ccccccc}
0 & 0 & 0 & 0 & 0 & 0 & 0 \\
0 & 1 / \eta & 0 & 0 & 0 & 0 & 0 \\
0 & 0 & 1 / \eta & 0 & 0 & 0 & 0 \\
0 & 0 & 0 & 1 / \eta & 0 & 0 & 0 \\
0 & 0 & 0 & 0 & 1 / C & 0 & 0 \\
0 & 0 & 0 & 0 & 0 & 1 / C & 0 \\
0 & 0 & 0 & 0 & 0 & 0 & 1 / C
\end{array}\right]\left\{\begin{array}{l}
P \\
\tau_{x y} \\
\tau_{y z} \\
\tau_{x z} \\
M_{x} \\
M_{y} \\
M_{z}
\end{array}\right\}
$$

where: $\eta=$ viscosity, and $\mathrm{C}=.00001 \eta$

The element does not generate a consistent mass matrix and only the lumped mass matrix is available. The sloshing effects and associated mode characteristics can be studied using this element.

In D-Fluid elements, the free surface is handled using gravity springs having the equivalent stiffness $K_{S}$. The springs are added to each node of the fluid element and their function is to keep the free surface in place. To better understand this special spring effect, the free surface motion is illustrated using the simplified U-Tube model shown in Fig. 1. As indicated in the figure, when the left fluid column is pushed down a distance of $\Delta \mathrm{h}$, the corresponding mass of displaced fluid $\left(M_{D}\right)$ will be:

$$
M_{D}=\Delta h A \rho
$$


where, $A=$ cross-sectional area of the tube, and $\rho=$ fluid density. Thus, it can be simply concluded that the force required to hold the fluid in place $\left(\mathrm{F}_{\mathrm{D}}\right)$ will be equal to the weight of the displaced fluid mass:

$$
F_{D}=M_{D} g
$$

where, $g=$ acceleration due to gravity. The stiffness at the fluid surface corresponding to this force $\left(\mathrm{K}_{\mathrm{S}}\right)$ can therefore be defined as:

$$
K_{S}=\frac{F_{D}}{\Delta h}=\rho A g
$$

This equation is generalized as:

$$
K_{s}=\rho A_{f}\left(g_{x} C_{x}+g_{y} C_{y}+g_{z} C_{z}\right)
$$

where, $A_{f}=$ area of the face of the element, $g_{i}=$ acceleration in the $i$ direction, and $C_{i}=i^{\text {th }}$ component of the normal to the face of the element. The above expression suggests adding springs from each node of the fluid element to ground. Added springs have positive constants at the nodes on top of the element and have negative constants for those located on bottom surface. Hence, at the interior nodes within the liquid domain, these positive and negative effects cancel out and by this means the added springs only operate at the fluid free surface. At the base of the vessel the fluid nodes on the boundary are coupled to those of the structure in order to couple the motions of different domains and also to keep the fluid from leaking out. As a result, the negative springs defined for the nodes located on the base boundary have no effect.

The natural periods and associated mode shapes of the structure are computed by solving the eigenvalue problem (Chopra 2000). The stored fluid is modeled using eight-node brick fluid elements and the structural domain is modeled using four-node quadrilateral shell elements 
having six degrees of freedom (translations and rotations) per node. Fluid and shell domain should be meshed in such a way that the location of each node of the fluid domain on the interface coincides exactly with that of the corresponding shell element. Then, these coincident nodes must be coupled in the direction normal to the interface in order to get equal displacements in radial direction for both fluid and shell nodes located on the interface. However, tangential relative displacements should be possible to happen and therefore, no coupling needs to be assigned in any other direction. Fluid nodes should be coupled at all interfaces with containing structure; this includes coupling the fluid nodes located at the interface with the tank floor in the direction perpendicular to the floor. However, to couple the nodes located at the conical portion of the vessel, first the radial coordinates (in the cylindrical coordinate system) of the fluid-shell nodes located along the cone interface should be rotated by the cone angle ensuring that all nodes are aligned perpendicular to the cone shell. Then, the rotated nodes can be coupled in the direction normal to the surface. The conical section of the vessel has one interface with the cylindrical side shell at the top and one with the concrete floor at the bottom. In order to define liquid domain boundary condition correctly, shell nodes located along these two boundary lines should be coupled to the corresponding fluid nodes in two orthogonal directions. This is performed by introducing a new coordinate system at these locations.

The interaction of the contained fluid and the structure at an interface causes the hydrodynamic pressure to apply a force exerted on the structure and the structural motions produce an effective fluid load.

The equation of motion for a typical MDOF system subjected to external forces can be written as follows:

$$
\left\{F_{I}\right\}+\left\{F_{D}\right\}+\left\{F_{S}\right\}=\left\{F^{a}\right\}
$$


where, $\left\{F_{I}\right\},\left\{F_{D}\right\},\left\{F_{S}\right\}$ are inertia, damping and stiffness force vectors, respectively and $\left\{F^{a}\right\}$ denotes the applied load vector. Substituting each force vector with the corresponding term will result in the following equation:

$$
[M]\{\ddot{u}\}+[C]\{\dot{u}\}+[K]\{u\}=\left\{F^{a}\right\}
$$

where, $[M],[C]$, and $[K]$ are mass, damping and stiffness matrices, respectively and $\{u\},\{\dot{u}\}$, and $\{\ddot{i i}\}$ are displacement, velocity, and acceleration vectors, respectively. In order to derive the fluid-structure coupling formulations, $\left\{F^{a}\right\}$ in eq. (8) is separated into the fluid pressure load acting at the interface $\left\{F_{e}^{p r}\right\}$ and resultant of all other forces $\left\{F_{e}\right\}$. Thus, the elemental structural equation can be rewritten as:

$$
\left[M_{e}\right]\left\{\ddot{u}_{e}\right\}+\left[C_{e}\right]\left\{\dot{u}_{e}\right\}+\left[K_{e}\right]\left\{u_{e}\right\}=\left\{F_{e}\right\}+\left\{F_{e}^{p r}\right\}
$$

The fluid pressure load vector $\left\{F_{e}^{p r}\right\}$ at fluid-structure interface $S$ can be determined by integrating the pressure over the interface surface area as:

$$
\left\{F_{e}^{p r}\right\}=\int_{S}\left\{N^{\prime}\right\} p\{n\} d(S)
$$

in which, $\left\{N^{\prime}\right\}$ is the shape functions used to discretize the structural displacement components (obtained from the structural element), $p$ is the fluid pressure, and $\{n\}$ is the normal at the fluid boundary. Using the finite element approximating shape functions for the spatial variation of the fluid pressure, one can write:

$$
p=\{N\}^{T}\left\{p_{e}\right\}
$$

where, $\{N\}$ is the shape function for fluid pressure and $\left\{p_{e}\right\}$ is the nodal pressure vector. It should be noted that this shape function is the same as the one employed to discretize the nodal 
pressure DOF in the corresponding elements. At the fluid-structure interaction surface, linear quadrilateral shape functions corresponding to a four-node surface element are employed. Full details regarding this shape function can be found in Zienkiewicz and Taylor (2000).

Substituting eq. (11) into eq. (10) gives:

$$
\left\{F_{e}^{p r}\right\}=\int_{S}\left\{N^{\prime}\right\}\{N\}^{T}\{n\} d(S)\left\{p_{e}\right\}
$$

By definition, the coupling matrix $\left[R_{e}\right]$ relates the pressure of the fluid and the forces on the fluid-structure interface. Therefore one can write:

$$
\left\{F_{e}^{p r}\right\}=\left[R_{e}\right]\left\{p_{e}\right\}
$$

By comparing the eqs. (12) and (13), the coupling matrix is found to be:

$$
\left[R_{e}\right]^{T}=\int_{S}\left\{N^{\prime}\right\}\{N\}^{T}\{n\} d(S)
$$

Finally, the dynamic elemental equation of the structure is obtained by substituting eq. (13) into eq. (9) as:

$$
\left[M_{e}\right]\left\{\ddot{u}_{e}\right\}+\left[C_{e}\right]\left\{\dot{u}_{e}\right\}+\left[K_{e}\right]\left\{u_{e}\right\}-\left[R_{e}\right]\left\{p_{e}\right\}=\left\{F_{e}\right\}
$$

The design spectrum in accordance with ASCE 7-10 (2010) is used for analysis purpose of elevated water tanks in this study. Using this proposed technique, the hydrodynamic pressure distribution in a three-dimensional space corresponding to the convective and impulsive terms is determined separately. As suggested by ACI 350.3 (2006), the damping ratios of 0.5 and 5 percent are assumed for convective and impulsive modes, respectively. The damping ratio is defined as the ratio of actual damping to critical damping for a particular mode of vibration. Concrete shafts of three different ranges of lateral stiffness $\left(K_{s}\right)$; lower range $\left(K_{s}=1.3 E 8 N / m\right)$, median range $\left(\mathrm{K}_{\mathrm{s}}=4.5 \mathrm{E} 9 \mathrm{~N} / \mathrm{m}\right)$ and upper range $\left(\mathrm{K}_{\mathrm{s}}=1.4 \mathrm{E} 10 \mathrm{~N} / \mathrm{m}\right)$ are chosen for this study. The 
considered stiffness range covers a wide spectrum of shaft stiffness variation typically found in practice today. In the present study, the lateral shaft stiffness is estimated by hand calculations as per ACI 371R (2008) assuming a cantilever beam type deflection for the tank/pedestal system:

$$
K_{s}=\frac{3 E_{c} I_{c}}{L_{g}^{3}}
$$

In which, $E_{c}$ is the modulus of elasticity of concrete; $I_{c}$ is the moment of inertia of the gross concrete section about the centroidal axis, neglecting reinforcement and $L_{g}$ is the distance from base to centroid of the stored water.

The parameters selected for this study are shown in Fig. 2. The parameters are defined as follows:

$\mathrm{rt}$ : Radius of the cylindrical steel shell

Rroot : Radius of the supporting shaft

htop : Freeboard (distance between the water free surface and the roof)

h3 : Height of water in the cylindrical portion of the tank

hc : Height of the conical portion of the tank

hshaft : Height of the supporting shaft

tcyl : Average thickness of the cylindrical portion of the tank

tcon : Average thickness of the conical portion of the tank

tfloor : Thickness of the tank's floor

tshaft : Thickness of the concrete shaft wall

teta : Cone angle

In total, 243 elevated tank models were created throughout this parametric study. On each model, two different types of analysis; modal and spectral were performed. The tank configurations considered for this study cover "Rroot/h3" ratios varying from 0.40 to 1.30 , and "hc/h3" ratios varying from 0.40 to 1.00 . This results in a wide range of tank capacities 
encompassing form the smallest to the largest conical elevated tanks ever built in practice. It should be noted that for the cone angle "teta" to remain at $45^{\circ}$, the ratio of "rt/h3" should be selected equal to the summation of the ratios "hc/h3" and "Rroot/h3" for each tank configuration under consideration.

The value of parameter "htop" is considered to be equal to $0.50 \mathrm{~m}$ for all elevated tank models analyzed. In addition, the value of parameter "teta" is kept constant at $45^{\circ}$ for all models considered throughout this parametric study.

FE models are created using the parametric model specifically written for this parametric study using the ANSYS ${ }^{\circledR}$ command lines. For all models, the mass densities of $1000 \mathrm{~kg} / \mathrm{m}^{3}$, $7898 \mathrm{~kg} / \mathrm{m}^{3}$, and $2400 \mathrm{~kg} / \mathrm{m}^{3}$ are assumed for water, steel, and concrete materials, respectively. All structural parts are modeled assuming linear elastic material. The Young's modulus of 200 $\mathrm{GPa}$ and $24.86 \mathrm{GPa}$ are used for steel and concrete materials, respectively. Furthermore, Poisson's ratios corresponding to steel and concrete materials are assumed to be 0.30 and 0.16 , respectively.

In general, as the mesh size is reduced, that is, as the number of elements is increased, the accuracy of the solution increases. However, the goal here is to refine the mesh to achieve the required accuracy by using only as many degrees of freedom as necessary. In order to find the optimum mesh size, a study was conducted in the preliminary phase of the research on the FE solution convergence considering different number of fluid elements. The mesh refinement was continued until the difference between the results obtained from one mesh and the previously refined mesh became negligible. The results of the study showed that using the following number of element divisions would lead to a desired degree of accuracy and a converged solution in calculating the hydrodynamic pressure. 
Number of element divisions along the:

Tank (both cylindrical and conical portions) and shaft circumferences: $\mathrm{n}=56$

Tank diameter at $\theta=0^{\circ}$ and $90^{\circ}: \mathrm{n}=28$

Height of water in the cylindrical portion of the tank: $n=14$

Height of the conical portion of the tank: $n=14$

Freeboard height: $\mathrm{n}=2$

Shaft height: between $n=13$ to 26 depending on the shaft height

This will result in a total of 16,464 fluid elements. Using a finer mesh scheme had no considerable effect on the estimated hydrodynamic pressure.

Based on the results obtained from this parametric study, a number of pressure graphs presenting the pressure distribution along the height of the tank wall are determined for both convective and impulsive components. The graphs are plotted as normalized wall pressure $\left(\mathrm{P}_{\mathrm{c}} / \mathrm{S}_{\mathrm{ac}} / \mathrm{W}_{\mathrm{L}}\right)$ or $\left(\mathrm{P}_{\mathrm{i}} / \mathrm{S}_{\mathrm{ai}} / \mathrm{W}_{\mathrm{L}}\right)$ versus water depth ratio $\left(\mathrm{h} / \mathrm{h}_{\mathrm{l}}\right)$, where " $\mathrm{P}_{\mathrm{c}}$ " and "Pi" represent the convective and impulsive pressure values in $\mathrm{N} / \mathrm{m}^{2}$, respectively. " $\mathrm{S}_{\mathrm{ac}}$ " and " $\mathrm{S}_{\mathrm{ai}}$ " are the spectral accelerations in $\mathrm{m} / \mathrm{s}^{2}$ corresponding to the convective and impulsive modes, respectively. " $\mathrm{W}_{\mathrm{L}}$ " is the weight of the contained water in Newton $(\mathrm{N})$ and " $h$ " is the height of the water inside the tank in meter $(\mathrm{m})$.

Having obtained the hydrodynamic pressure value at the cone base of the wall, $\mathrm{P}_{\text {Cone Base }}$ (at $\mathrm{h} / \mathrm{hl}=-1.0$ ), the hydrodynamic pressure distribution can be calculated on the tank base floor. The hydrodynamic pressure distribution on the tank floor shows an anti-symmetric variation pattern about the centroidal axis of the shaft in both convective and impulsive modes starting from + $\mathrm{P}_{\text {Cone Base }}$ at one end and ending with - $\mathrm{P}_{\text {Cone Base }}$ at the opposite end. As indicated in Fig. 3, the pressure applied on the tank floor has an upward direction on one half and downward direction 
on the other half with the maximum magnitudes $\left(\mathrm{P}_{\max }=\mathrm{P}_{\text {Cone Base }}\right)$ occurring along the cone/floor interface and a zero value occurring along the centroidal axis of the tank. Obtained results show that the hydrodynamic pressure on the floor follows an almost linear fashion vertically and a cosine pattern horizontally. As a result, the overturning moment due to the hydrodynamic pressure applied on the vessel base can be calculated by integrating the pressure over the floor area as follows:

assuming $d A=r d r d \theta$

$$
\begin{aligned}
M_{\text {quarter }} & =\int_{r=0}^{R_{\text {root }}} \int_{\theta=0}^{\frac{\pi}{2}} P_{\text {ConeBase }}\left(\frac{r}{R_{\text {root }}}\right)(r \cos \theta)(\cos \theta) r d r d \theta=\int_{r=0}^{R_{\text {root }}} \int_{\theta=0}^{\frac{\pi}{2}} P_{\text {ConeBase }}\left(\frac{r^{3}}{R_{\text {root }}}\right)\left(\frac{1+\cos 2 \theta}{2}\right) d r d \theta \\
& =\frac{P_{\text {ConeBase }}}{R_{\text {root }}}\left(\frac{R_{\text {root }}^{4}}{4}\right)\left(\frac{1}{2} \theta+\frac{1}{4} \sin 2 \theta\right)\left(\theta=0 \text { to } \frac{\pi}{2}\right)=\frac{P_{\text {ConeBase }}}{R_{\text {root }}}\left(\frac{R_{\text {root }}^{4}}{4}\right)\left(\frac{\pi}{4}\right)=\frac{\pi}{16} P_{\text {ConeBase }} R_{\text {root }}^{3}
\end{aligned}
$$

where, $M_{\text {quarter }}$ is the overturning moment corresponding to the one quarter of the base area. Total overturning moment can therefore be calculated as:

$$
M_{\text {total }}=4 M_{\text {quarter }}=\frac{\pi}{4} P_{\text {ConeBase }} R_{\text {root }}^{3}
$$

The corresponding mode shapes associated with the impulsive and convective components are provided in Fig. 4. As obvious from the figure, the sloshing mode is associated with vertical water surface displacements which are antisymmetric about the axis of rotation. No shell vibration is observed during the animation of this mode. This is in accordance with the well-known assumption of decoupling the sloshing and the shell motions in liquid-containing structures. The obtained impulsive mode can be classified as a translational $\cos \theta$-type modein which the entire tank behaves like a vertical beam.

In plotting the pressure graphs, the values of spectral accelerations $\left(\mathrm{S}_{\mathrm{ai}}\right.$ and $\left.\mathrm{S}_{\mathrm{ac}}\right)$ were calculated based on the ASCE 7-10 design spectrum using the natural periods of impulsive and convective modes, respectively obtained from the FE modal analysis. In doing so, the values of 
"Importance factor" I=1 and "Response modification coefficient" R=1 were chosen as per ASCE 7-10. Furthermore, the mapped spectral accelerations $\left(S_{S}\right.$ and $\left.S_{1}\right)$ were selected as $1.5 \mathrm{~g}$ and $0.6 \mathrm{~g}$, respectively. Site class "A", representing a site with hard rock soil was also assumed in determining these accelerations.

\section{Numerical model verification}

In order to validate the proposed numerical model, the free vibration response of a smallscale aluminum conical tank is obtained using the current FE technique and the results are compared with the experimental values reported by El Damatty et al. (2005). In their study, shake table testing as well as numerical analysis were conducted to determine the dynamic properties of a conical tank specimen. The geometry and corresponding finite element model used in the present study is indicated in Fig. 5. Aluminum shell is modeled as linear elastic material with the following properties:

Young's modulus $=69 \mathrm{GPa}$

Poisson's ratio $=0.33$

Density $=2700 \mathrm{~kg} / \mathrm{m}^{3}$

The natural frequencies and effective masses corresponding to both sloshing and liquid-shell vibration modes are obtained using current FE technique and the results are summarized in Table 1. In the table, $R_{i}$ is defined as the ratio of the effective modal mass in the direction under consideration to the total mass of the water. As shown in the table, the obtained FE results are in excellent agreement with experimental results verifying that the current method can be employed with high accuracy to study the fluid-structure interaction problems of conical liquid containers. To provide further validation of results calculated from FE simulation, the meridional variations 
of the first two liquid-shell modes evaluated experimentally are also plotted in Fig. 6 and are compared with those obtained from the current study. The plotted drifts are in a radial direction. It can be observed from the figure that there is a significant change in the mode shape pattern between the conical and cylindrical portions of the tank. It can further be observed from the figure that there is an excellent agreement between the results of this study and those reported by El Damatty et al. (2005). As a result, the same FE methodology is employed to study the behavior of liquid-filled conical elevated tanks in this study.

\section{Scope of the research}

The following assumptions and limitations are assumed in the current study:

a) Tanks are assumed to be rigidly anchored to the rigid ground such that no sliding or uplift may occur. As a result, the effect of soil-structure interaction is not considered.

b) The translational degrees of freedom of the nodes located at the shaft base are fully restrained however the rotations are free.

c) Study of the convective response of the contained liquid is based on the linear theory of sloshing. As a result, the convective pressure measured at the free surface can be interpreted as the product of fluid unit weight and the sloshing height at the corresponding location.

d) Only the effect of horizontal ground motion is considered and the effect of vertical motion is ignored.

e) Top vessel is assumed to be made of steel while the supporting shaft is made of reinforced concrete. All structural materials are assumed to behave as linear elastic and therefore the effect of material nonlinearity is neglected. 
f) The inclined cone angle of the lower portion of the combined vessel is assumed as $45^{\circ}$ for all models considered in this study.

g) The tank floor is usually made of a concrete dome. Due to element shape irregularities occurring during mesh generation of fluid domain located inside the conical portion of the vessel, the floor is modeled as a flat shell. The effects of such simplification were investigated in this study and it was found to have little effect on the total response. The fundamental mode shapes (both impulsive and convective) of the tank are not generally influenced by the shape of the tank's floor.

h) The geometric nonlinearity effect is taken into account in FE analysis of the models. This procedure requires that strain increments must be restricted to maintain accuracy. As a result, the total load is broken into smaller steps.

i) The pressure graphs provided are only valid for the range of parameters considered through this study as mentioned before as follows: shaft stiffness $\left(\mathrm{K}_{\mathrm{s}}\right)$ ranges from $1.3 \mathrm{E} 8 \mathrm{~N} / \mathrm{m}$ to $1.4 \mathrm{E} 10$ $\mathrm{N} / \mathrm{m}$, "Rroot/h3" ratio ranges from 0.40 to 1.30 , "hc/h3" ratio ranges from 0.40 to 1.00 , "tfloor" ranges from 250 to $450 \mathrm{~mm}$, "tcon" ranges from 12.26 to $49.02 \mathrm{~mm}$, and "tcyl" ranges from 4.41 to $17.66 \mathrm{~mm}$. Parameter ranges assumed in this study are chosen based on a large data base that covers dimensional and geometrical properties of typical elevated tanks found in today's practice.

j) Conical and cylindrical sections of the tanks are considered to be of constant thickness along their heights, respectively. "tcon/tcyl" ratio is kept constant as 2.78 in all considered models.

k) Energy dissipation due to the effect of wall friction and fluid viscosity is not considered in this study as a conservative approach. 


\section{Sensitivity studies}

Prior to performing the parametric study, a set of sensitivity analyses were carried out to investigate the sensitivity of the proposed quantities $\left(\mathrm{P}_{\mathrm{c}} / \mathrm{S}_{\mathrm{ac}} / \mathrm{W}_{\mathrm{L}}\right)$ and $\left(\mathrm{P}_{\mathrm{i}} / \mathrm{S}_{\mathrm{a}} / \mathrm{W}_{\mathrm{L}}\right)$ to different parameters such as floor thickness "tfloor" and plate thickness along the cylindrical "tcyl" and conical "tcon" portions of the vessel.

\subsection{Effect of floor thickness variation}

In order to examine the effect of floor thickness variation on the normalized pressure distribution, three different tank models having different floor thicknesses are considered. The assumed tank models have the following properties in common:

$$
\begin{aligned}
\mathrm{rt}=12.42 \mathrm{~m}, \quad \text { htop }=0.5 \mathrm{~m}, \quad \text { hshaft }=22.0 \mathrm{~m}, \quad \text { hc }=4.28 \mathrm{~m}, \quad \mathrm{~h} 3=6.85 \mathrm{~m}, \\
\text { tshaft }=381 \mathrm{~mm}, \quad \text { tcon }=24.51 \mathrm{~mm}, \quad \text { tcyl }=8.83 \mathrm{~mm}, \quad \text { Rroot }=8.13 \mathrm{~m}
\end{aligned}
$$

The tank has the full capacity of $4755 \mathrm{~m}^{3}(1.26 \mathrm{MG})$. Three different values of floor thickness "tfloor" equal to $250 \mathrm{~mm}, 330 \mathrm{~mm}$, and $450 \mathrm{~mm}$ are chosen and the resulting normalized pressure distribution corresponding to the convective $\left(\mathrm{P}_{c} / \mathrm{S}_{\mathrm{ac}} / \mathrm{W}_{\mathrm{L}}\right)$ and impulsive $\left(\mathrm{P}_{\mathrm{i}} / \mathrm{S}_{\mathrm{ai}} / \mathrm{W}_{\mathrm{L}}\right)$ components along the height of the tank wall are calculated (see Fig. 7). As obvious from Fig. 7, normalized pressure distribution is almost independent of the floor thickness variation. This trend is observed for both convective and impulsive response components. As previously mentioned, the sloshing height can also be estimated as $\mathrm{P}_{\mathrm{c}} / \gamma$ where $\gamma$ is the unit weight of fluid.

\subsection{Effect of plate thickness variation}


In this section the effect of plate thickness variation on the normalized pressure distribution is investigated by selecting three different tank models having different plate thicknesses. The following properties are common to the three elevated tank models considered:

$$
\begin{array}{llll}
\mathrm{rt}=12.42 \mathrm{~m} \quad \text { htop }=0.5 \mathrm{~m} \quad \text { hshaft }=22.0 \mathrm{~m} \quad \mathrm{hc}=4.28 \mathrm{~m} & \text { h3 }=6.85 \mathrm{~m} \\
\text { tfloor }=330 \mathrm{~mm} & \text { tshaft }=381 \mathrm{~mm} & \text { Rroot }=8.13 \mathrm{~m}
\end{array}
$$

The geometry of the tank is the same as that explained in the previous subsection. However, in order to examine the effect of plate thickness variation on the proposed normalized pressure quantity, three different values of plate thicknesses "tcyl" and "tcon" are chosen.

As mentioned above, three different tank models are created by doubling $(2 \mathrm{t})$ and halving (0.5t) the plate thicknesses "tcyl" and "tcon". The original plate thicknesses (t) corresponding to the cylindrical and conical portions of the vessel are $8.83 \mathrm{~mm}$ and $24.51 \mathrm{~mm}$, respectively. The resulting normalized pressure distributions along the height of the tank wall corresponding to these three models are indicated in Fig. 8.

Consequently, as indicated in Fig. 8, the proposed normalized pressure quantity can be considered independent of the plate thickness variation. This is true for both convective and impulsive terms.

As a result, it can be concluded that by normalizing the obtained pressure values with respect to the spectral accelerations (Sac and Sai), one can omit the sensitivity of the hydrodynamic pressure to the variation of floor and plate thicknesses. This reduces the number of parameters required to perform the parametric study yielding considerable reduction in computational efforts.

The normalized convective and impulsive pressure graphs obtained through this parametric study corresponding to the three different ranges of shaft stiffness considered can be found in 
Fig. 9 and Figs. C.1-C.26 in Moslemi (2011). The pressure graphs are calculated for "Rroot/h3" ratios varying from 0.40 to 1.30 , and "hc/h3" ratio of 0.4 . The graphs show the normalized pressure distribution along the height of the tank wall. The heights corresponding to the cone/cylinder interfaces are also shown in the figures by horizontal dashed lines. Graphs for other ranges of " $\mathrm{h}_{\mathrm{c}} / \mathrm{h} 3$ " (from 0.4 to 1.0 ) are provided in Moslemi (2011).

As shown in Fig. 9, it can be noticed that as the Rroot/h3 ratio increases, the normalized impulsive wall pressure decreases gradually while keeping a similar pressure distribution pattern over the tank height. Observing the given convective pressure graphs, it can be noted that an increase in the Rroot/h3 ratio results in a decrease in the normalized convective wall pressure for the upper sections of the tank, whereas a reverse trend is observed for the lower sections. Moreover, it can be noticed that the convective pressure reaches its maximum value at the water free surface while the impulsive pressure reaches its peak value at the cone/cylinder interface with the zero magnitude occurring at the free surface.

\section{Accuracy of the proposed pressure graphs}

In order to examine the capability of the proposed pressure graphs for estimating the seismic response of liquid-filled conical elevated tanks, a verification study is conducted on two randomly selected elevated tank models namely models A and B as will be described. It is important to note that the effect of hydrodynamic pressure applied on the tank's base floor is taken into account in estimating the results listed in Tables 2 and 3.

\subsection{Elevated tank model A}


The tank configuration considered for this part of verification study is that of an actual elevated tank situated in the U.S. The selected tank is a $1945 \mathrm{~m}^{3}(0.51 \mathrm{MG})$ elevated water storage tank with dimensions as specified in Fig. 10. Other geometric properties not indicated in the figure are expressed below:

side shell thickness: $6.9 \mathrm{~mm}$

cone thickness: $11.4 \mathrm{~mm}$

tank floor thickness: $533 \mathrm{~mm}$

shaft thickness: $300 \mathrm{~mm}$

A distributed mass (total mass $115 \times 10^{3} \mathrm{~kg}$ ) accounting for the equivalent mass of the platforms inside the pedestal with their full live load is applied at $20.3 \mathrm{~m}$ above the base. In addition, a distributed mass balance of $111 \times 10^{3} \mathrm{~kg}$ accounting for the mass of the components of the tank (e.g. roof, access tube, etc.) is assigned at the ring beam level. The finite element idealization of the tank is also indicated in Fig. 10.

The peak values of shear and overturning moment at the base of the tank due to lateral seismic excitation are obtained using three different methods; FE time-history analysis, "current practice" method, and finally the method presented in this study using the proposed parametric pressure graphs. The results of FE-time history analysis are used to assess the adequacy of the other two methods mentioned above.

The tank is subjected to the horizontal component of 1940 El-Centro ground motion with the peak ground acceleration of $0.32 \mathrm{~g}$. The direct integration method with an integration time step of 0.005 second is used to determine the transient response of the selected elevated tank model under a random ground excitation. The maximum absolute response values obtained through FE time-history analysis are given in Table 2. 
Using the two-mass idealization approach recommended by "current practice", two modes of vibration with the natural periods of $4.21 \mathrm{sec}$ and $1.01 \mathrm{sec}$ corresponding to the fundamental convective and impulsive modes, respectively are identified. These values are in excellent agreement with the natural periods of $4.23 \mathrm{sec}$ and $1.11 \mathrm{sec}$ obtained from a modal FE analysis.

The natural period corresponding to the fundamental sloshing mode $\left(T_{c}\right)$ can also be compared with the following equation based on ACI 350.3 (2006) code of practice:

$$
T_{c}=\frac{2 \pi \sqrt{D}}{\sqrt{3.68 g \tanh \left[3.68\left(\frac{H_{e q}}{D}\right)\right]}}
$$

where $D$ is the free surface diameter of the tank, $g$ is acceleration due to gravity, and $H_{e q}$ is the equivalent height of a cylindrical tank with the same volume and the same free surface diameter. On this basis, the fundamental convective period is calculated as $4.13 \mathrm{~s}$ for model A which is in good agreement with the one derived from FE analysis. The above equation can be employed for other tanks with different dimensions.

In calculating the response values using the "current practice" method, the values of "Importance factor", $\mathrm{I}=1$ and "Response modification coefficient" $\mathrm{R}=1$ are used. Furthermore, the design spectrum scaled to a peak ground acceleration of $0.32 \mathrm{~g}$ to correspond with the earthquake record used in FE time-history analysis is employed. The mapped spectral accelerations $\left(S_{S}\right.$ and $\left.S_{1}\right)$ for Imperial Valley location are determined as $1.5 \mathrm{~g}$ and $0.6 \mathrm{~g}$, respectively per ASCE 7-10. Moreover, site class "A" representing a site with hard rock soil is chosen to correspond with the rigid ground boundary condition assumed in FE modeling of the tank. 
Using the formulations given in the "current practice", the base shear values of $687 \mathrm{kN}$ and $4968 \mathrm{kN}$ corresponding to the convective and impulsive terms, respectively are obtained. Furthermore, based on the "current practice" approach, the base moment values of $30208 \mathrm{kNm}$ and $195727 \mathrm{kNm}$ are found for convective and impulsive components, respectively. The calculated convective and impulsive terms may be combined by SRSS method to determine the total response values of the tank-pedestal system.

As a third and final method, the seismic response of the elevated tank model is calculated by applying the appropriate pressure values obtained from the proposed pressure graphs. The selected tank model has the shaft stiffness of about $1.3 \mathrm{E} 8 \mathrm{~N} / \mathrm{m}$, and the aspect ratios Rroot/h3 and hc/h3 of 0.43 and 0.42 , respectively. Therefore, the appropriate pressure values are obtained by interpolating between the values determined from the curves corresponding to the aspect ratios of $\operatorname{Rroot} / \mathrm{h} 3=0.4$ and 0.51 and also $\mathrm{hc} / \mathrm{h} 3=0.4$ and 0.475 .

Entering the natural periods of $4.23 \mathrm{sec}$ and $1.11 \mathrm{sec}$ corresponding to the fundamental convective and impulsive modes, respectively into the El-Centro response spectrum, the spectral acceleration of $\mathrm{S}_{\mathrm{a}}=0.27 \mathrm{~g}$ for impulsive and $\mathrm{S}_{\mathrm{ac}}=0.06 \mathrm{~g}$ for convective mode are obtained. The $5 \%$ and $0.5 \%$-damped response spectra scaled to the peak ground acceleration of $0.32 \mathrm{~g}$ are used for impulsive and convective modes, respectively. Substituting these spectral accelerations (Sai and Sac) along with the weight of stored water $\left(\mathrm{W}_{\mathrm{L}}\right)$ into the normalized pressure values obtained from interpolation, the actual hydrodynamic pressure values can be computed. The resulting convective and impulsive pressures are shown in Fig. 11.

As shown in the figure, the convective pressure has the peak value of $6.2 \mathrm{kPa}$ at water free surface, while the impulsive pressure has the peak value of $21.8 \mathrm{kPa}$ at cone/cylinder interface. For the sake of simplicity, the equivalent linear approximation may be used instead of the actual 
pressure distribution by equating the area under the actual pressure distribution curve to the area under the idealized linear approximation curve, as indicated in Fig. 11.

The obtained pressure values are applied to the model with a cosine variation pattern around the tank circumference and the corresponding values of base shear and base moment due to convective and impulsive water components are obtained by performing a simple static analysis. The empty tank's inertial effects are included by performing a spectral analysis on the empty structure using the El-Centro response spectrum. Using only the fundamental mode having the natural period of $\mathrm{T}=0.42 \mathrm{sec}$ is sufficient to accurately estimate the seismic response of the empty tank.

The response of the empty tank is considered to be in phase with the response due to the vibration of the impulsive water. As a result, the total impulsive response may be determined by simply adding these two response components together. However, the total response of the tank may be calculated by combining the total impulsive response explained above with the response due to convective behaviour using a SRSS combination method. The obtained impulsive and convective response values are given in Table 2.

As presented in the table, in general using both "current practice" and proposed pressure graphs has resulted in a precise estimation of base shear and base moment values under both convective and impulsive vibrations. However, "current practice" has underestimated the convective base shear and base moment by about $5 \%$ and $2 \%$, respectively.

Utilizing the proposed pressure graphs has led to a slight overestimation of the convective base shear and base moment by only $3 \%$ and $1 \%$, respectively. This approach also produces a reasonable overestimation of the impulsive base shear and base moment of approximately $9 \%$ and $10 \%$, respectively which seems appropriate for design applications. 


\subsection{Elevated tank model B}

The particular tank configuration considered is that of an actual storage tank located in the U.S. with the full capacity of $7571 \mathrm{~m}^{3}$ (2 MG). This tank has three times more capacity as compared to model A. Other geometric properties are as follows:

$$
\begin{array}{llll}
\mathrm{rt}=15.3 \mathrm{~m} & \text { htop }=0.914 \mathrm{~m} & \text { hshaft }=25.370 \mathrm{~m} \quad \text { hc }=6.165 \mathrm{~m} & \text { h3 }=7.763 \mathrm{~m} \\
\text { tfloor }=330 \mathrm{~mm} & \text { tshaft }=380 \mathrm{~mm} & \text { Rroot }=9.14 \mathrm{~m}
\end{array}
$$

The equivalent weight of platforms inside the shaft with their full live load is accounted for by adding a distributed mass (total mass $715 \times 10^{3} \mathrm{~kg}$ ) applied at $15.6 \mathrm{~m}$ above the base. Moreover, a mass balance of $438 \times 10^{3} \mathrm{~kg}$ corresponding to the weight of the components (e.g. roof, access tube, etc.) is applied around the ring beam as a distributed mass.

The same earthquake record considered for model A is used. The calculated maximum absolute response values are listed in Table 3.

The base shear values of $2156 \mathrm{kN}$ and $32778 \mathrm{kN}$ are obtained using "current practice" corresponding to the convective and impulsive terms, respectively. Based on the "current practice", the base moment values of $91588 \mathrm{kNm}$ and $1215668 \mathrm{kNm}$ are obtained for convective and impulsive terms, respectively.

As a third approach, the seismic response of the elevated tank model is determined by applying the appropriate pressure values obtained from the proposed pressure graphs. The selected tank model has the shaft stiffness of about $4.5 \mathrm{E} 9 \mathrm{~N} / \mathrm{m}$, and the aspect ratios Rroot/h3 and hc/h3 of 1.3 and 0.90 , respectively. Therefore, the appropriate pressure values are calculated by interpolating between the values determined from the curves corresponding to the aspect ratios of hc/h3=0.85 and 0.925 . 
Using the El-Centro response spectrum, the spectral accelerations of $\mathrm{S}_{\mathrm{ai}}=0.88 \mathrm{~g}$ and $\mathrm{S}_{\mathrm{ac}}=0.067 \mathrm{~g}$ are obtained corresponding to the fundamental impulsive and convective periods of $0.51 \mathrm{sec}$ and $6.2 \mathrm{sec}$, respectively. Again, the natural convective period is in full agreement with the one obtained from eq. (18). The convective and impulsive pressures determined from the proposed pressure graphs are shown in Fig. 12. The structural response values corresponding to these pressures are listed in Table 3.

As presented in the table, an accurate estimation of results is obtained using the proposed pressure graphs for both convective and impulsive response components of the medium-capacity tank model under consideration. Employing the proposed pressure graphs has resulted in a slight overestimation of the convective base shear and base moment by only $7 \%$. A reasonable overestimation of around $7 \%$ and $13 \%$ is also obtained using this procedure for impulsive base shear and base moment, respectively. As a result, a designer can use this approach with confidence to accurately estimate the response values in seismic design of liquid-filled conical elevated tanks.

\section{Conclusions}

A comprehensive parametric study was carried out on liquid-filled conical elevated tanks using a detailed FE technique in a three-dimensional space. Based on the results of this study, the convective and impulsive pressure values can be separately determined along the height of the tank wall for typical elevated water tanks found in practice today.

The study covered a wide range of tank dimensions and geometries commonly found in today's practice. The effects of deciding parameters such as shaft stiffness, tank radius, shaft radius, height of contained water, tank height and so on were taken into consideration. 
Through this parametric study, the normalized pressure distribution graphs corresponding to the convective and impulsive components were obtained for a wide range of varying parameters by carrying out FE spectral analyses on a large number of conical elevated tanks. Spectral analyses were performed using ASCE 7-10 design spectrum. The graphs were plotted as normalized wall pressure $\left(\mathrm{P}_{\mathrm{c}} / \mathrm{S}_{\mathrm{ac}} / \mathrm{W}_{\mathrm{L}}\right)$ or $\left(\mathrm{P}_{\mathrm{i}} / \mathrm{S}_{\mathrm{ai}} / \mathrm{W}_{\mathrm{L}}\right)$ against water depth ratio $\left(\mathrm{h} / \mathrm{h}_{\mathrm{l}}\right)$.

Based on the results of the sensitivity studies conducted, it was concluded that the proposed normalized pressure quantities $\left(\mathrm{P}_{\mathrm{c}} / \mathrm{S}_{\mathrm{ac}} / \mathrm{W}_{\mathrm{L}}\right.$ and $\left.\mathrm{P}_{\mathrm{i}} / \mathrm{S}_{\mathrm{ai}} / \mathrm{W}_{\mathrm{L}}\right)$ were almost insensitive to the variations of plate thickness along the cylindrical and conical portions of the vessel. This study also demonstrated the independence of the proposed normalized pressure quantities from the variations of tank's floor thickness. Thus, it was concluded that the sensitivity of the hydrodynamic pressure to the floor and plate thickness variations can be removed by normalizing the hydrodynamic pressure with respect to the spectral accelerations.

The validity of the calculated pressure graphs was verified by performing a comparison study between the proposed pressure graph method as the investigated method and the preverified FE time history method as the control method. For comparison purposes, the obtained results were also compared with those recommended by "current practice". Based on the results of this verification study, it was concluded that the proposed normalized pressure graphs could be utilized with high level of accuracy for seismic design of liquid-filled conical elevated tanks.

\section{Acknowledgement}

Financial support received by the Natural Sciences and Engineering Research Council of Canada (NSERC) through the Discovery grant program to the third author under the operating grant No. 46690 is gratefully acknowledged. 


\section{References}

American Concrete Institute (ACI) Committee 350. 2006. Seismic design of liquid-containing concrete structures and commentary, ACI 350.3-06, Environmental engineering concrete structures, Farmington Hills, MI, U.S.A.

American Society of Civil Engineers (ASCE). 2010. Minimum design loads for buildings and other structures, Structural Engineering Institute, ASCE/SEI 7-10, Reston, V.A.

American Concrete Institute (ACI) Committee 371. 2008. Guide for the analysis, design and construction of elevated concrete and composite steel-concrete water storage tanks, ACI 371R-08, Farmington Hills, MI, U.S.A.

Chopra, A.K. 2000. Dynamics of structures: theory and applications to earthquake engineering. 2nd ed. Prentice-Hall.

Dieterman, H.A. 1993. Liquid-structure foundation interaction of slender water towers. Archive of Applied Mechanics, 63(3): 176-188.

Dutta, S.C. 1995. Torsional behaviour of elevated water tanks with reinforced concrete frametype stagings during earthquakes. Ph.D. thesis, Department of Civil Engineering, Indian Institute of Technology, Kanpur, India.

Dutta, S.C., Murty, C.V.R., and Jain, S.K. 1996. Torsional failure of elevated water tanks: the problems and some solutions. Paper No. 287. In Proceedings of the Eleventh World Conference on Earthquake Engineering, Acapulco, Mexico, 23-28 June 1996. Elsevier, Amsterdam.

Dutta, S.C., Jain, S.K., and Murty, C.V.R. 2000a. Assessing the seismic torsional vulnerability of elevated tanks with RC frame-type staging. Soil Dynamics and Earthquake Engineering, 19(3): 183-97. 
Dutta, S.C., Jain, S.K., and Murty, C.V.R. 2000b. Alternate tank staging configurations with reduced torsional vulnerability. Soil Dynamics and Earthquake Engineering, 19: 199-215.

El Damatty, A.A., Saafan, M.S., and Sweedan, A.M.I. 2005. Experimental study conducted on a liquid-filled combined conical tank model. Journal of Thin Walled Structures, 43: 1398-417.

Ghaemmaghami, A.R., Moslemi, M., and Kianoush, M.R. 2010. Dynamic behaviour of concrete liquid tanks under horizontal and vertical ground motions using finite element method. In Proceedings of the $9^{\text {th }}$ US National and $10^{\text {th }}$ Canadian Conf. on Earthquake Eng., Toronto, Canada.

Housner, G.W. 1963. The dynamic behavior of water tanks. Bulletin of the Seismological Society of America, 53(2): 381-389.

Haroun, M.A., and Ellaithy, H.M. 1985. Seismically induced fluid forces on elevated tanks. J. Tech. Topics Civil Eng., 1: 1-15.

Livaoglu, R., and Dogangun, A. 2005. Seismic evaluation of fluid-elevated tank foundation/soil systems in frequency domain. Struct. Eng. Mech., 21(1): 101-19.

Livaoglu, R., and Dogangun, A. 2006. Simplified seismic analysis procedures for elevated tanks considering fluid-structure-soil interaction. J. Fluids Struct., 22(3): 421-39.

Livaoglu, R., and Dogangun, A. 2007. Effects of foundation embedment on seismic behavior of the elevated tanks considering fluid-structure-soil interaction. Soil Dynamcs and Earthquake Engineering, 27: 855-863.

Moslemi, M. 2011. Seismic response of ground cylindrical and elevated conical reinforced concrete tanks. Ph.D. thesis, Civil Engineering, Ryerson University, Toronto, Ontario.

Moslemi, M., and Kianoush, M. R. 2012. Parametric study on dynamic behavior of cylindrical ground-supported tanks. Journal of Engineering Structures, 42: 214-230. 
Moslemi, M., Kianoush, M.R., and Pogorzelski, W. 2011. Seismic response of liquid-filled elevated tanks. Journal of Engineering Structures, 33(6): 2074-2084.

Rai, D.C. 2002. Elevated tanks. Earthquake Spectra - Bhuj India Earthquake Reconnaissance Report (ed. Jain, Lettis, Bardet, and Murty). EERI, Supplement A to Vol. 18: 279-295.

Sezen, H., and Whittaker, A.S. 2006. Seismic performance of industrial facilities affected by the 1999 Turkey earthquake. ASCE Journal of Performance of Constructed Facilities, 20(1): 2836.

Veletsos, A.S. 1974. Seismic effects in flexible liquid storage tanks. In Proceedings of the $5^{\text {th }}$ World Conf. Earthquake Eng., Rome, Italy, pp. 630-639.

Veletsos, A.S., Tang, Y., and Tang, H.T. 1992. Dynamic response of flexibly supported liquid storage tanks. ASCE Journal of Structural Engineering, 118: 264-283.

Zienkiewicz, O.C., and Taylor, R.L. 2000. The Finite Element Method, $5^{\text {th }}$ ed., ButterworthHeinemann: Boston, MA, Vol. 1. 
Table 1. Free vibration analysis results for the experimental tank model.

\begin{tabular}{ccccc}
\hline \multicolumn{2}{c}{ Current study } & \multicolumn{2}{c}{ El Damatty et al. (2005) } & \multirow{2}{*}{ Mode type } \\
\cline { 1 - 4 } $\mathbf{R}_{\mathbf{i}} \mathbf{( \% )}$ & Frequency $(\mathbf{H z})$ & $\mathbf{R}_{\mathbf{i}}(\mathbf{\%})$ & Frequency $\mathbf{( H z )}$ & \\
\hline 56.6 & 0.84 & 58.0 & 0.82 & Fundamental convective \\
\hline \multirow{2}{*}{ Negligible } & 15.11 & \multirow{2}{*}{ Negligible } & 15.60 & First liquid-shell mode \\
\cline { 2 - 5 } & 17.97 & & 18.40 & Second liquid-shell mode \\
\hline \multirow{2}{*}{41.5} & 42.36 & 40.7 & 43.50 & First cos $\theta$ mode \\
\hline
\end{tabular}


Table 2. Peak base shear and base moment response values for the elevated tank model A (small-capacity).

\begin{tabular}{ccccccccccccc}
\hline & \multicolumn{3}{c}{ Pressure graphs } & \multicolumn{3}{c}{ “Current practice” } & \multicolumn{3}{c}{ FE time-history } \\
\hline & \multicolumn{1}{c}{ Impulsive } & Convective & \multicolumn{2}{c}{ Impulsive } & Convective & Impulsive & Convective \\
\hline & Ratio & $\begin{array}{c}\text { Max } \\
\text { value }\end{array}$ & Ratio & $\begin{array}{c}\text { Max } \\
\text { value }\end{array}$ & Ratio & $\begin{array}{c}\text { Max } \\
\text { value }\end{array}$ & Ratio & $\begin{array}{c}\text { Max } \\
\text { value }\end{array}$ & Ratio & $\begin{array}{c}\text { Max } \\
\text { value }\end{array}$ & Ratio & $\begin{array}{c}\text { Max } \\
\text { value }\end{array}$ \\
\hline $\begin{array}{c}\text { Base } \\
\text { shear } \\
(\mathrm{kN})\end{array}$ & $\mathbf{1 . 0 9}$ & 5332 & $\mathbf{1 . 0 3}$ & 743 & $\mathbf{1 . 0 2}$ & 4968 & $\mathbf{0 . 9 5}$ & 687 & $\mathbf{1 . 0 0}$ & 4865 & $\mathbf{1 . 0 0}$ & 723 \\
\hline $\begin{array}{c}\text { Base } \\
\text { moment } \\
(\mathrm{kN} . \mathrm{m})\end{array}$ & $\mathbf{1 . 1 0}$ & 200668 & $\mathbf{1 . 0 1}$ & 30955 & $\mathbf{1 . 0 7}$ & 195727 & $\mathbf{0 . 9 8}$ & 30208 & $\mathbf{1 . 0 0}$ & 182080 & $\mathbf{1 . 0 0}$ & 30747 \\
\hline
\end{tabular}


Table 3. Peak base shear and base moment response values for the elevated tank model B

(medium-capacity).

\begin{tabular}{ccccccccccccc}
\hline & \multicolumn{3}{c}{ Pressure graphs } & \multicolumn{3}{c}{ "Current practice” } & \multicolumn{3}{c}{ FE time-history } \\
\hline & \multicolumn{1}{c}{ Impulsive } & Convective & \multicolumn{2}{c}{ Impulsive } & Convective & Impulsive & Convective \\
\hline & Ratio & $\begin{array}{c}\text { Max } \\
\text { value }\end{array}$ & Ratio & $\begin{array}{c}\text { Max } \\
\text { value }\end{array}$ & Ratio & $\begin{array}{c}\text { Max } \\
\text { value }\end{array}$ & Ratio & $\begin{array}{c}\text { Max } \\
\text { value }\end{array}$ & Ratio & $\begin{array}{c}\text { Max } \\
\text { value }\end{array}$ & Ratio & $\begin{array}{c}\text { Max } \\
\text { value }\end{array}$ \\
\hline $\begin{array}{c}\text { Base } \\
\text { shear } \\
(\mathrm{kN})\end{array}$ & $\mathbf{1 . 0 7}$ & 38036 & $\mathbf{1 . 0 7}$ & 2661 & $\mathbf{0 . 9 2}$ & 32778 & $\mathbf{0 . 8 7}$ & 2156 & $\mathbf{1 . 0 0}$ & 35548 & $\mathbf{1 . 0 0}$ & 2487 \\
\hline $\begin{array}{c}\text { Base } \\
\text { moment } \\
\text { kN.m) }\end{array}$ & $\mathbf{1 . 1 3}$ & 1492710 & $\mathbf{1 . 0 7}$ & 100163 & $\mathbf{0 . 9 2}$ & 1215668 & $\mathbf{0 . 9 7}$ & 91588 & $\mathbf{1 . 0 0}$ & 1320592 & $\mathbf{1 . 0 0}$ & 94023 \\
\hline
\end{tabular}




\section{FIGURE CAPTIONS}

Fig. 1. Simplified U-Tube fluid model.

Fig. 2. Parameters defined for the parametric study.

Fig. 3. Hydrodynamic pressure distribution on the tank's base floor; (a) Vertical distribution, (b) Horizontal distribution (View A).

Fig. 4. Fundamental mode shapes; (a) Convective, (b) Impulsive.

Fig. 5. Geometry of the experimental tank model; (a) Side view, adapted from El Damatty et al. (2005), (b) FE model used in present study.

Fig. 6. Meridional variation of the first two liquid-shell modes of the experimental model; (a) First liquid-shell mode, (b) Second liquid-shell mode.

Fig. 7. Pressure distribution over the tank wall (effect of floor thickness variation) (Cone angle $=$ $45^{\circ}$ ); (a) Convective pressure, (b) Impulsive pressure.

Fig. 8. Pressure distribution over the tank wall (effect of plate thickness variation) (Cone angle $=$ 45); (a) Convective pressure, (b) Impulsive pressure.

Fig. 9. Pressure distribution over the tank wall for $\mathrm{Ks}=4.5 \mathrm{E} 9 \mathrm{~N} / \mathrm{m}$ and $\mathrm{hc} / \mathrm{h} 3=0.4$ (Cone angle $=$ $45^{\circ}$ ); (a) Convective, (b) Impulsive.

Fig. 10. Elevated tank model A; (a) 3D FE model, (b) Tank geometry.

Fig. 11. Pressure distribution over the tank wall (elevated tank model A) $\left(\right.$ Cone angle $\left.=45^{\circ}\right)$; (a) Convective pressure, (b) Impulsive pressure.

Fig. 12. Pressure distribution over the tank wall (elevated tank model B) $\left(\right.$ Cone angle $\left.=45^{\circ}\right)$; (a) Convective pressure, (b) Impulsive pressure. 


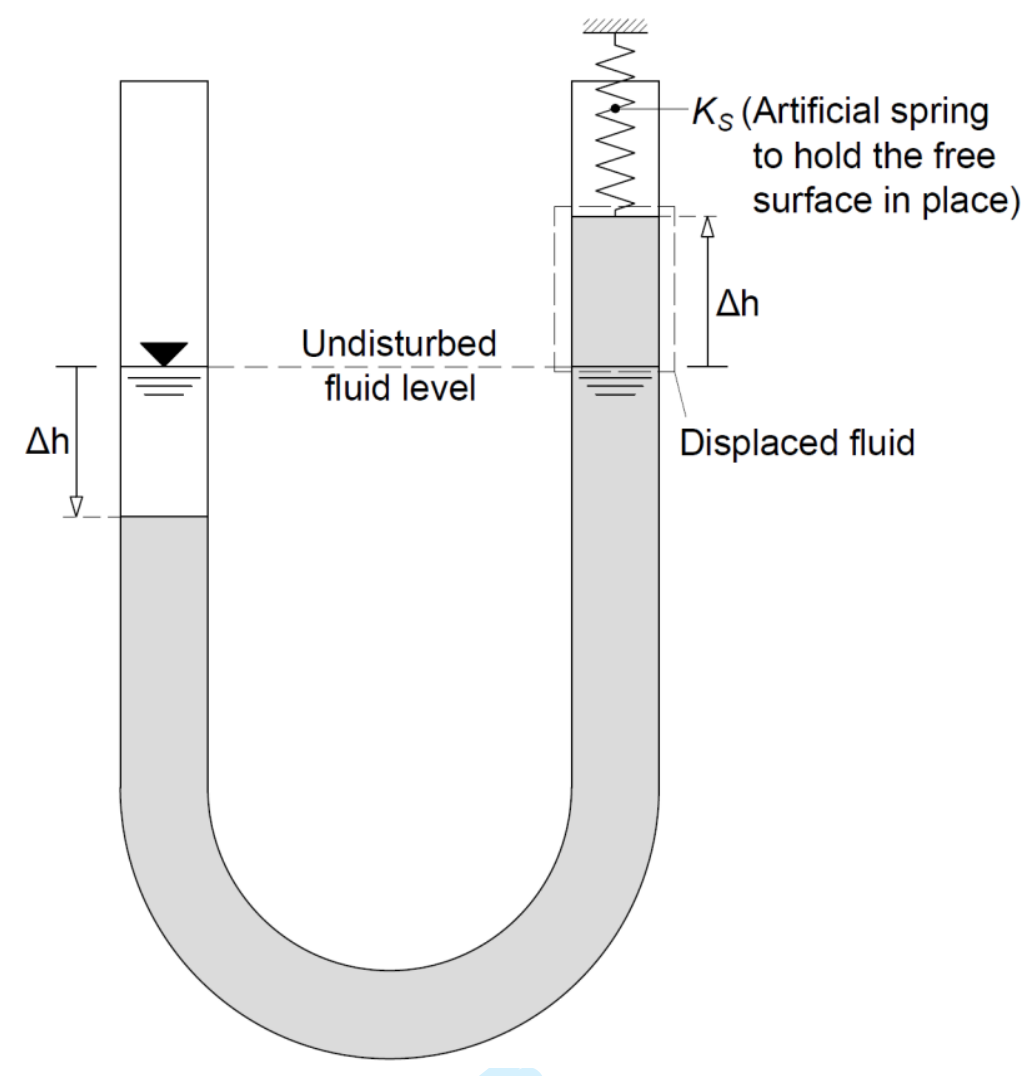




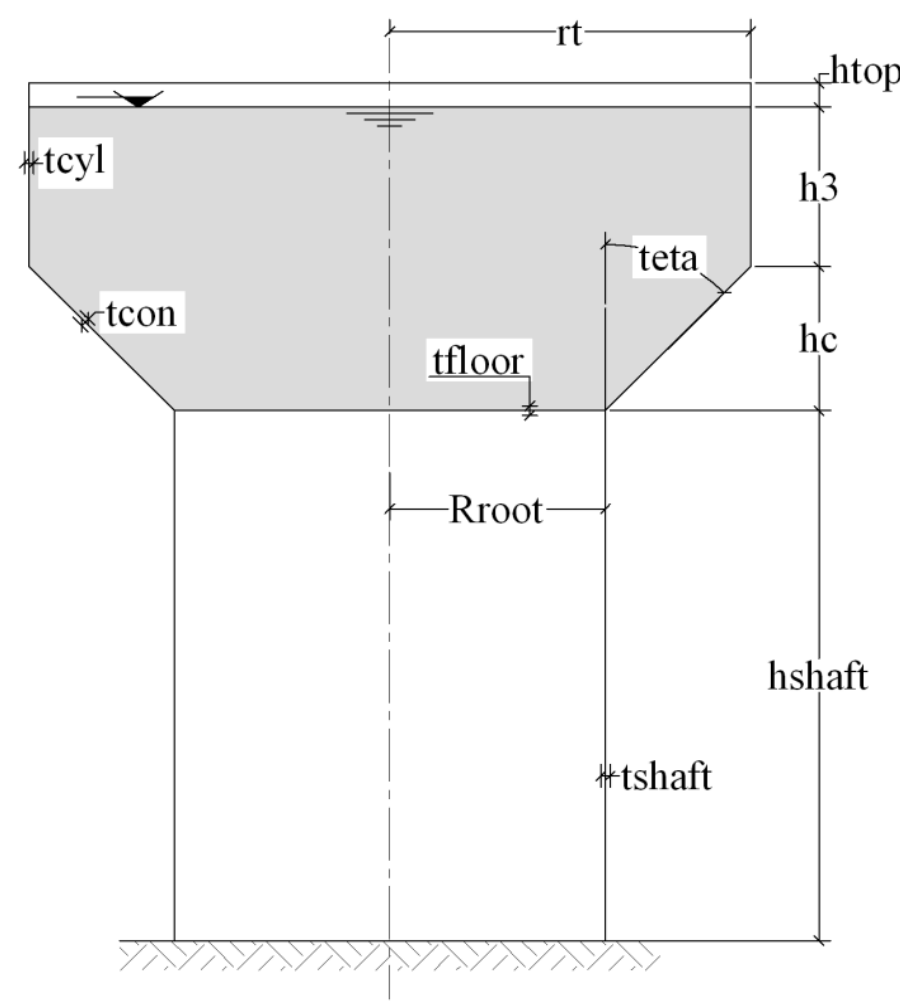



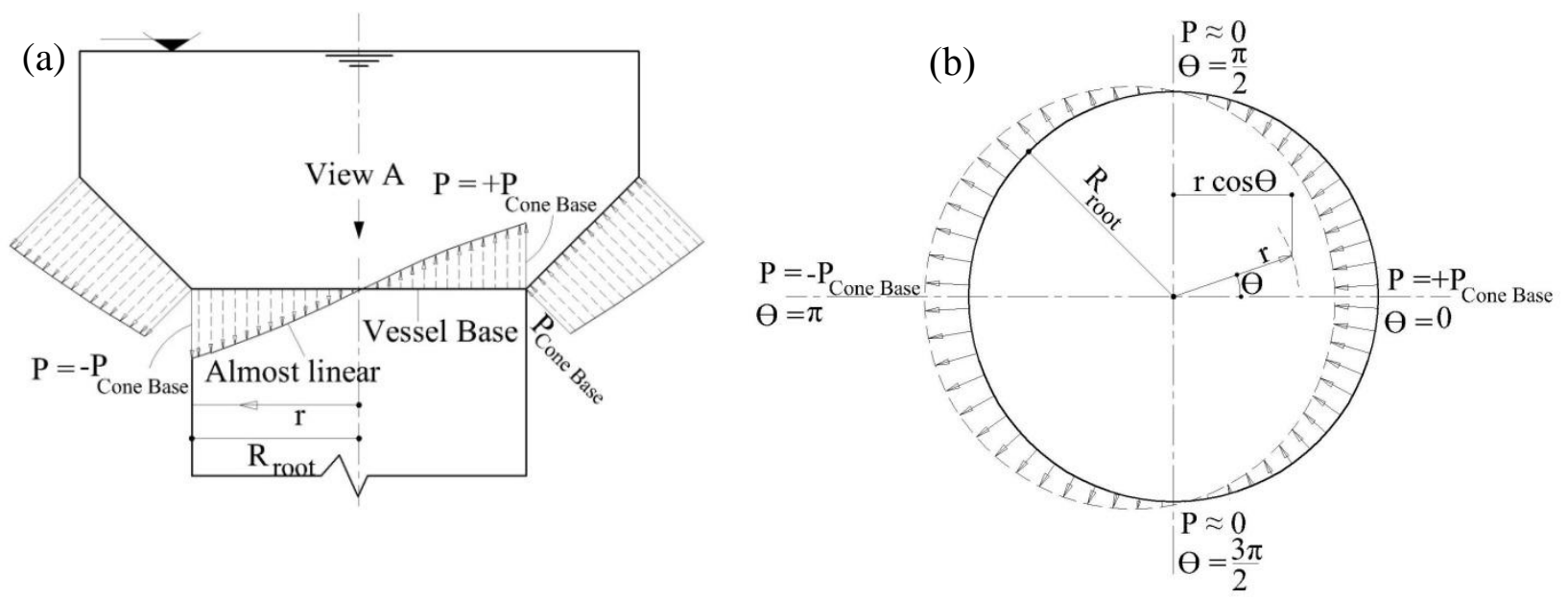
(a)

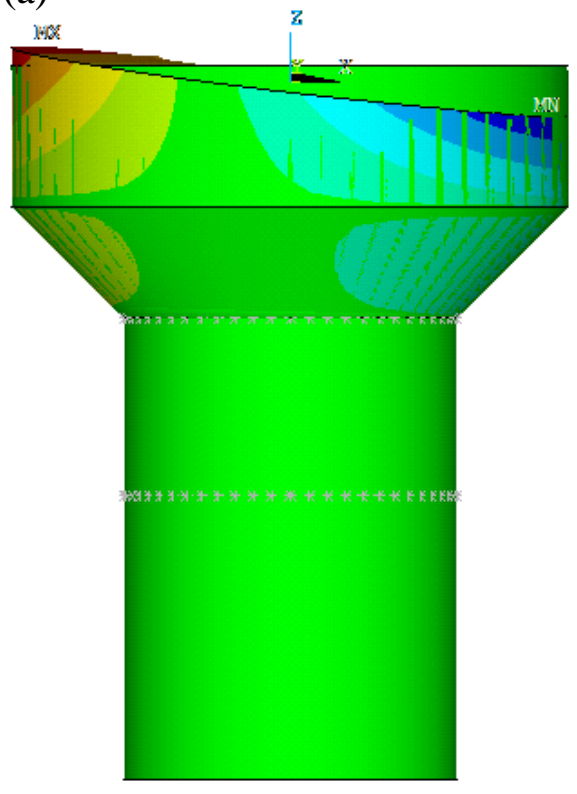

(b)

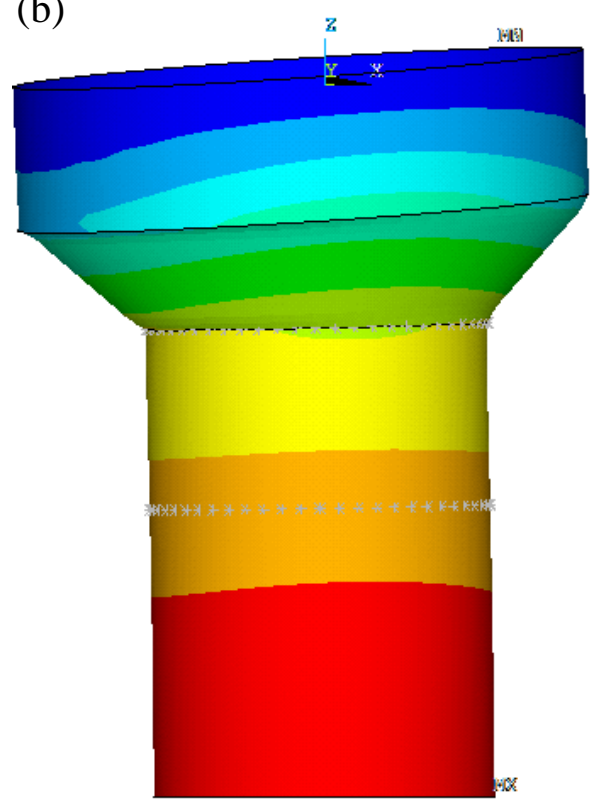




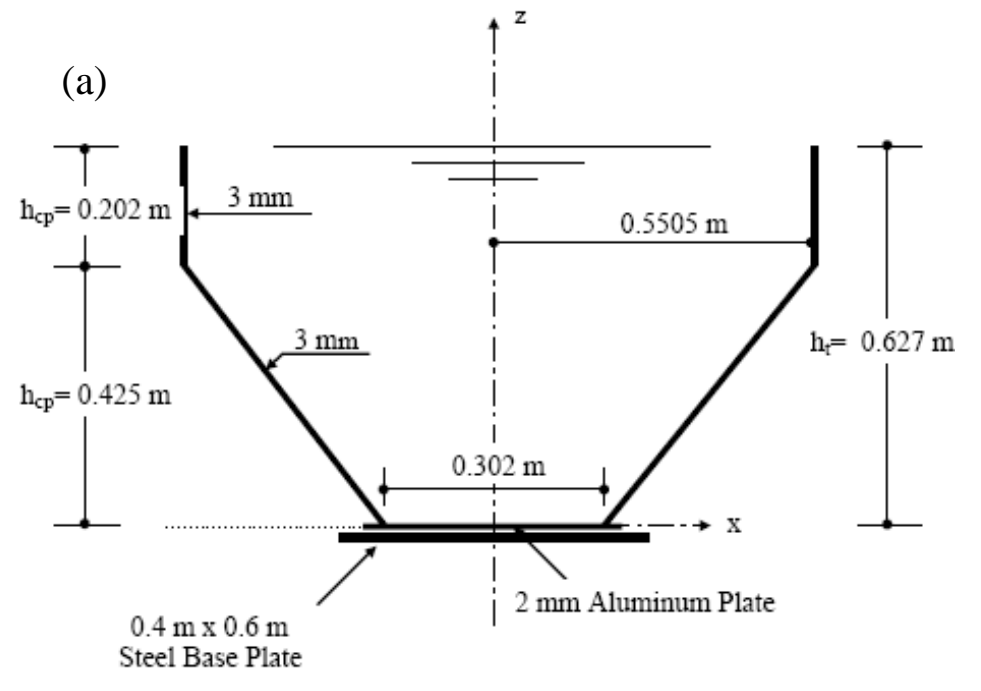

(b)

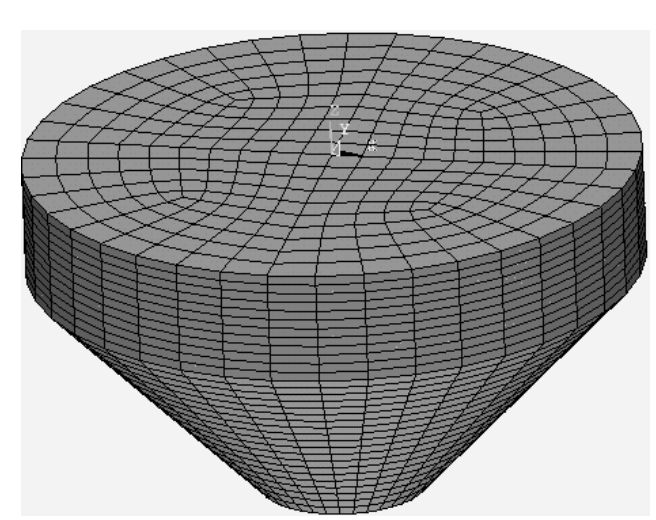



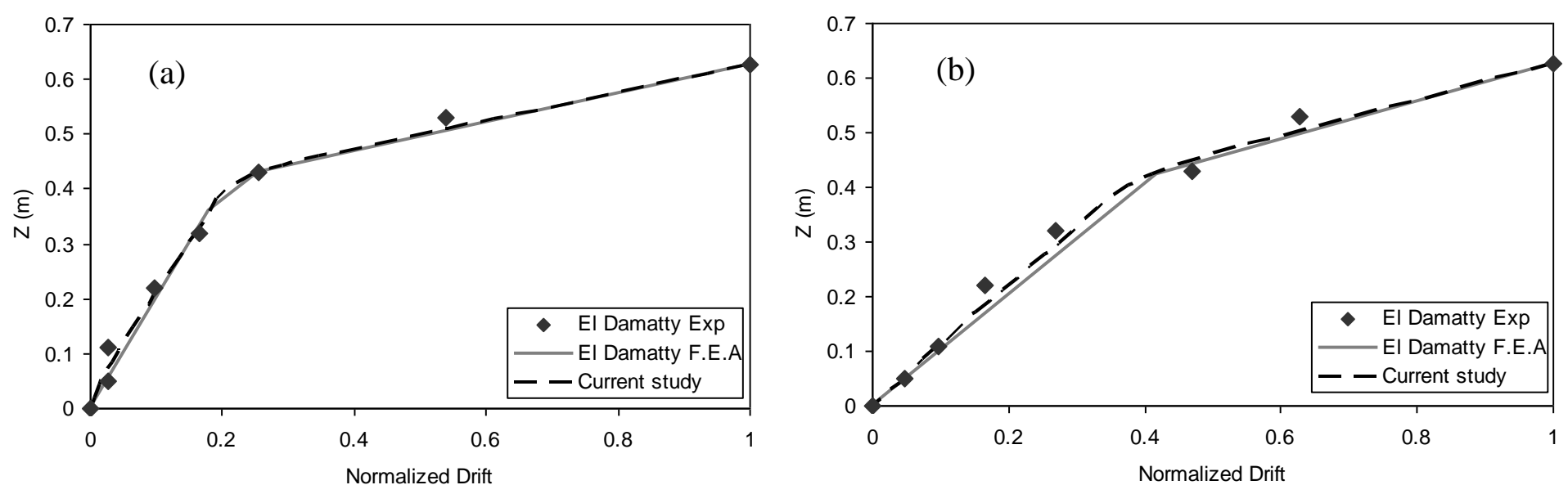

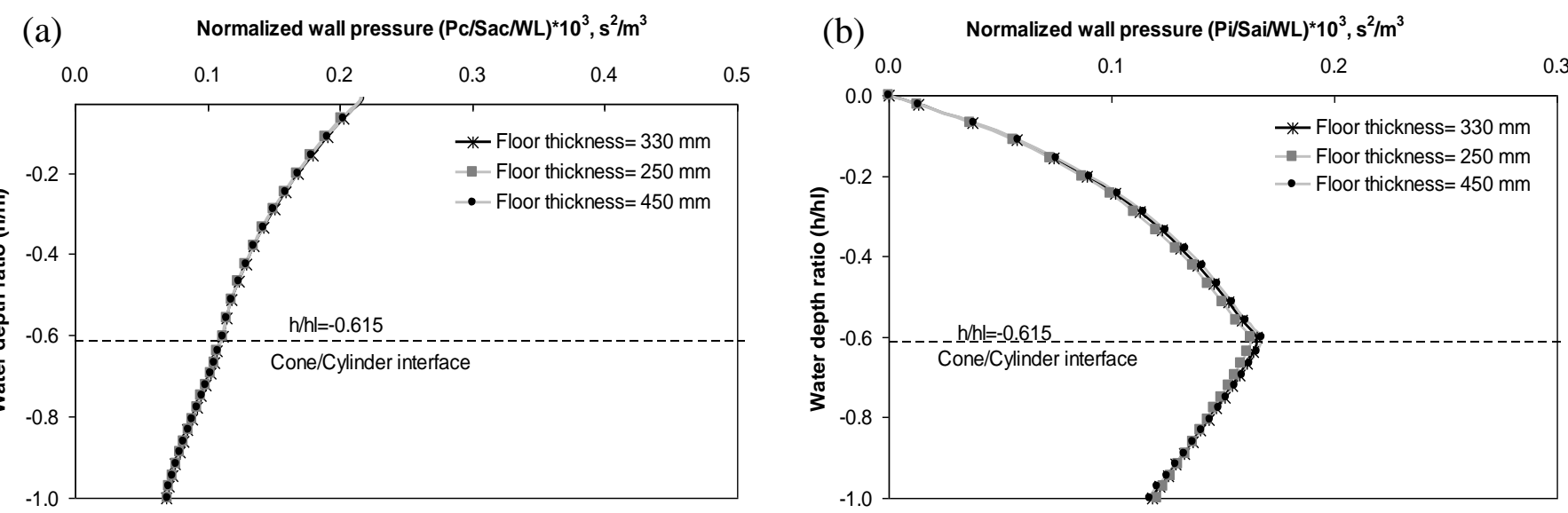
(a)

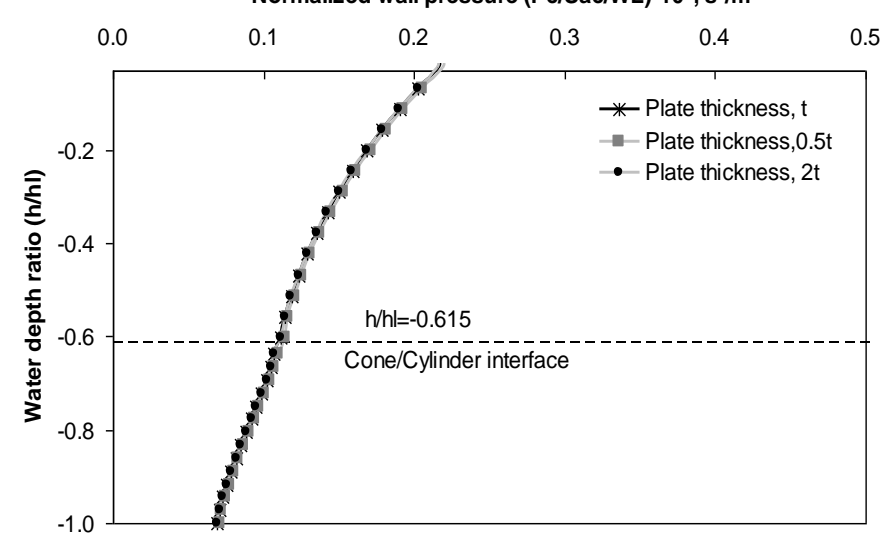

(b) Normalized wall pressure (Pi/Sai $/ W L)^{*} 10^{3}, \mathrm{~s}^{2} / \mathrm{m}^{3}$

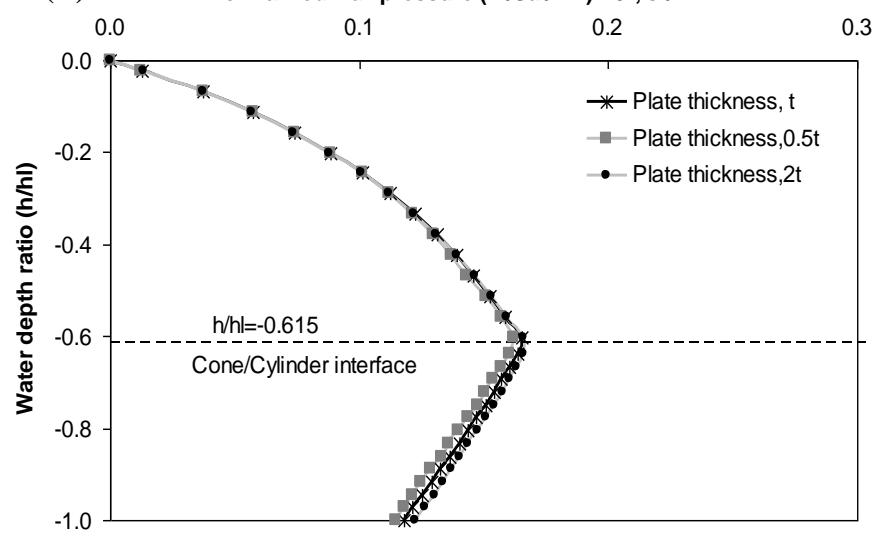


(a) Normalized wall pressure $(\mathrm{Pc} / \mathrm{Sac} / \mathrm{WL})^{\star} 10^{3}, \mathrm{~s}^{2} / \mathrm{m}^{3}$
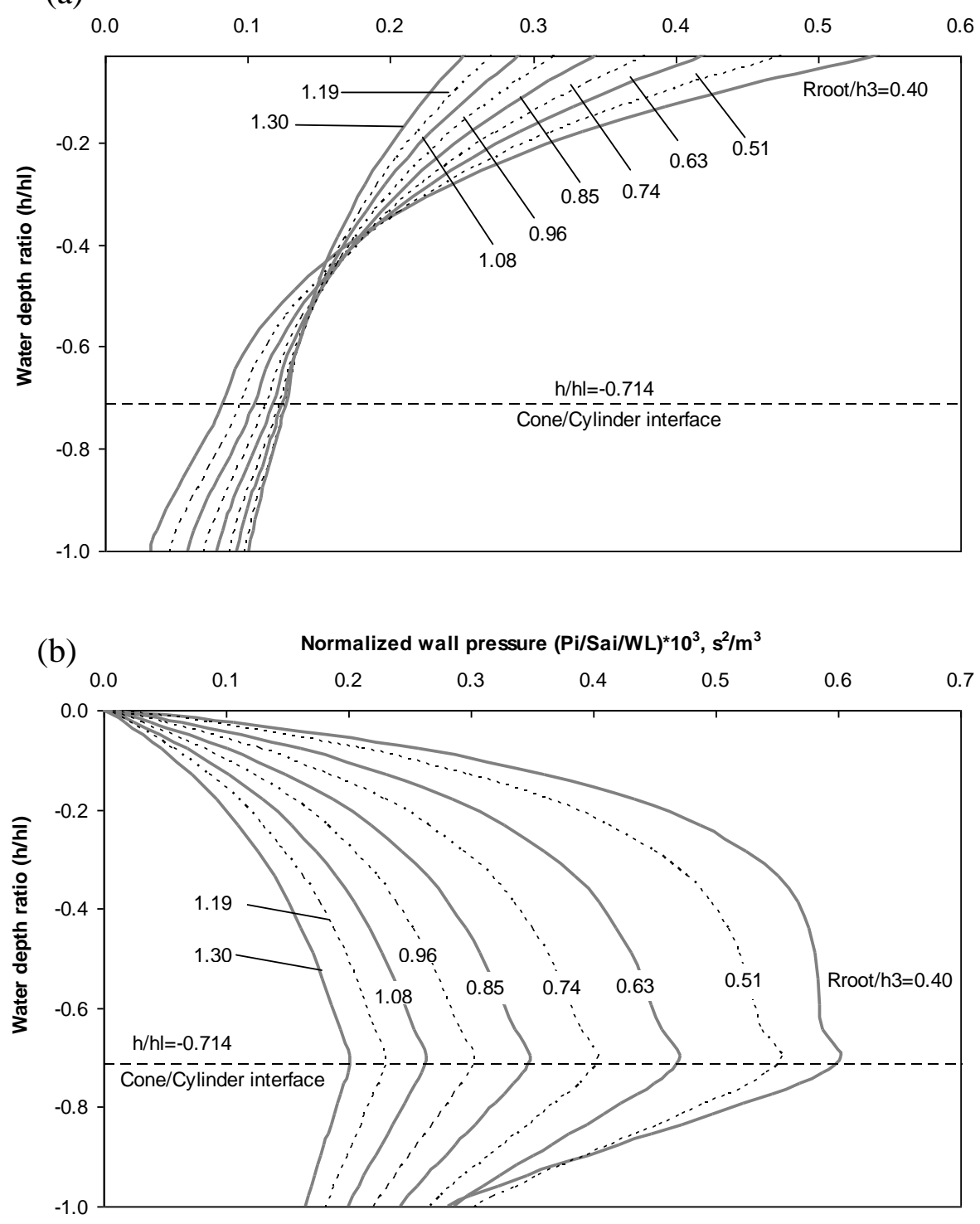
(a)

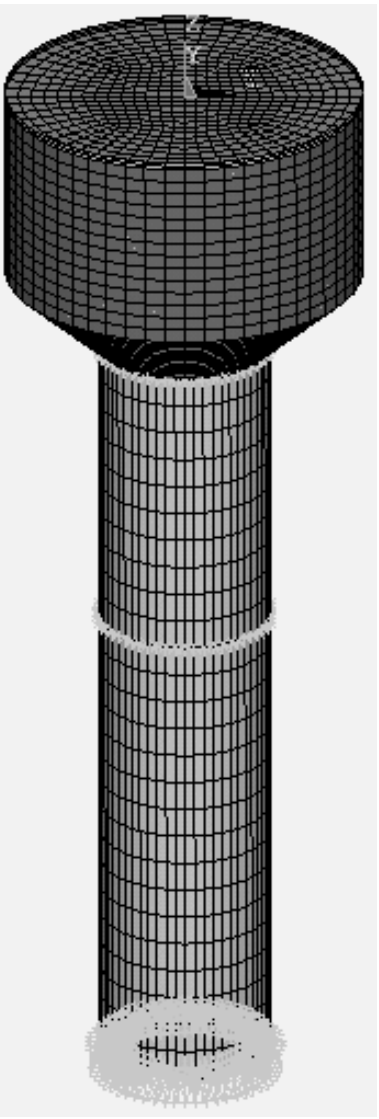

(b)
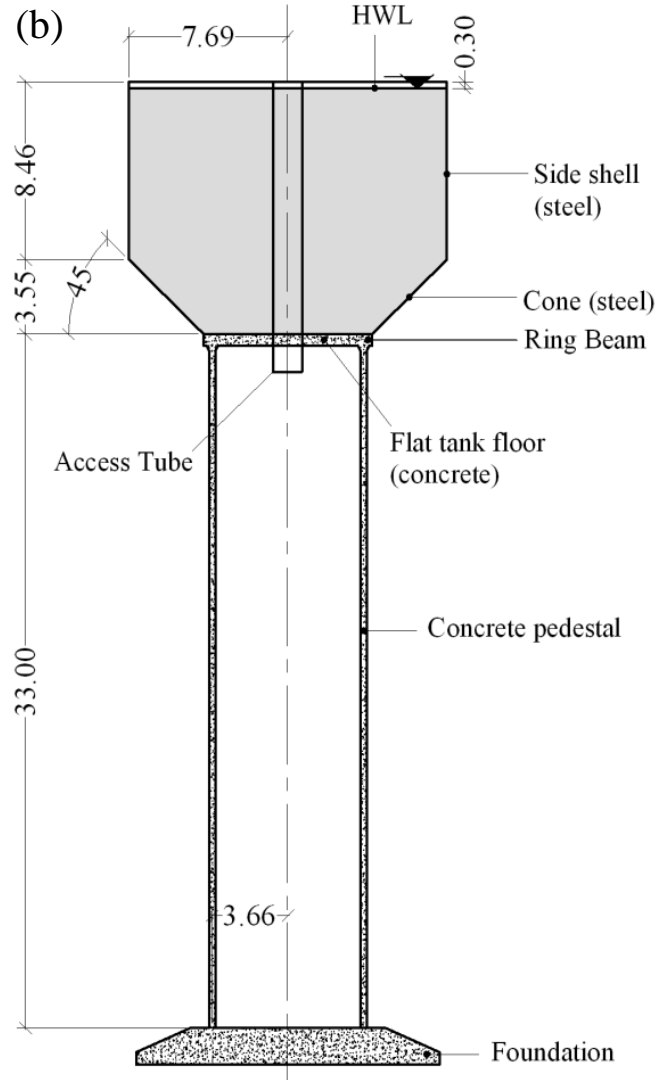

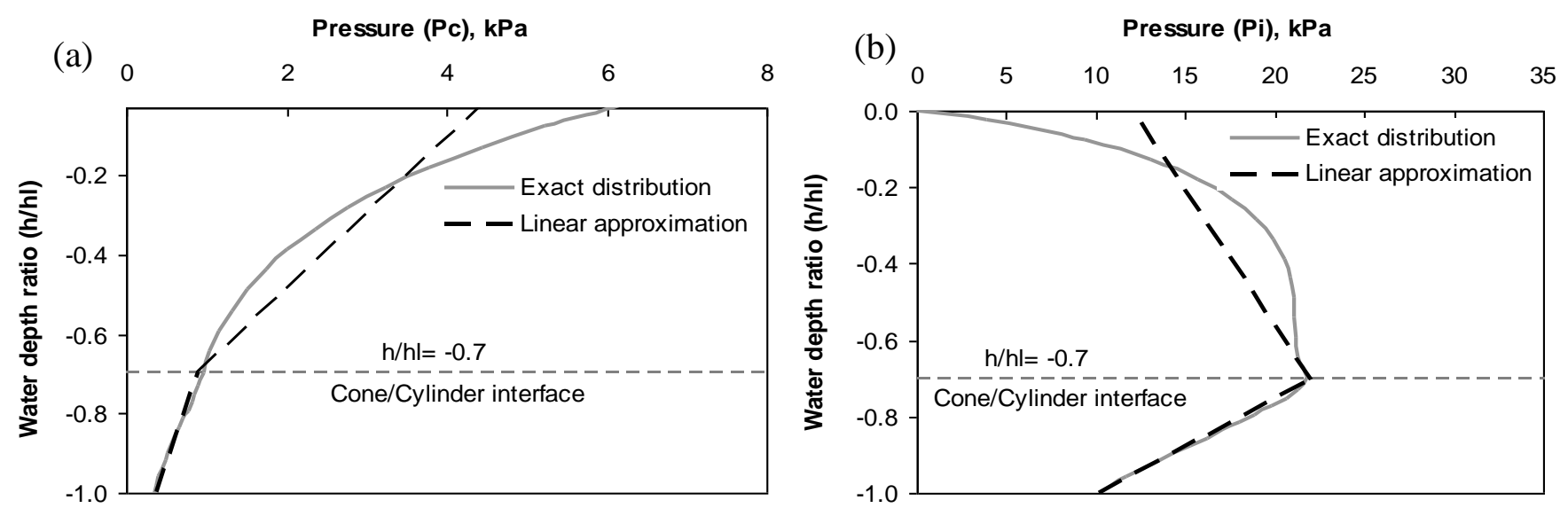

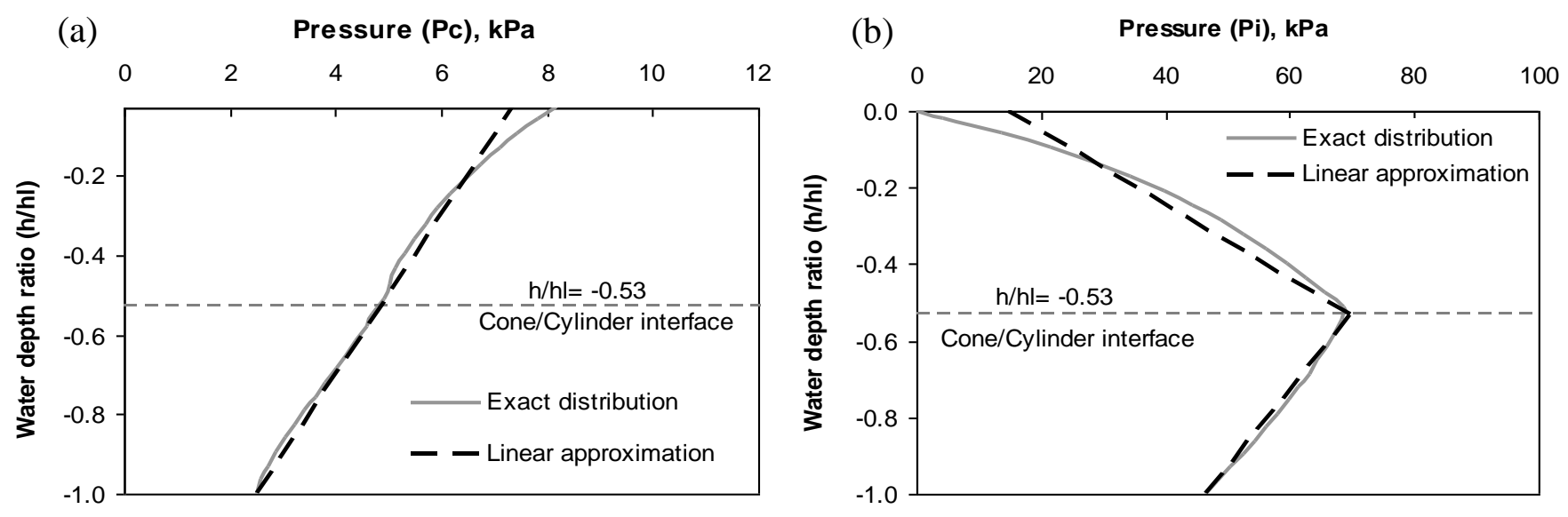